\title{
Diagnostic Gain from Surgical Biopsy for Interstitial Lung Disease - When is it Worth the Risk?
}

\author{
Diagnostischer Zugewinn der offenen Lungenbiopsie bei interstitiellen \\ Lungenerkankungen - wann ist das Risiko gerechtfertigt?
}

Authors

Institutions
C. Biancosino ${ }^{1,2}$, L. Welker ${ }^{3}$, M. Krüger ${ }^{1}$, S. Bölükbas ${ }^{2}$, I. Bittmann ${ }^{4}$, D. Kirsten ${ }^{3}$

${ }^{1}$ Department of Cardiac, Thoracic, Transplantation and Vascular Surgery, Hannover Medical School, Hannover, Germany 2 Department of Thoracic Surgery, Helios Klinikum Wuppertal, University Hospital Witten/Herdecke, Wuppertal, Germany

${ }^{3}$ Lung Clinic Grosshansdorf, Center for Pneumology and Thoracic Surgery, Grosshansdorf, Germany

${ }^{4}$ Institute of Pathology, Clinic Rotenburg, Rotenburg, Germany received 19.10.2015 accepted after revision 11.1.2016

\section{Bibliography}

Dol http://dx.doi.org/ 10.1055/s-0042-100551 Pneumologie 2016; 70: 205-210

(c) Georg Thieme Verlag KG Stuttgart · New York ISSN 0934-8387

\section{Corresponding author} Dr. Christian Biancosino Klinik für Thoraxchirurgie Helios Universitätsklinikum Wuppertal - Universität Witten/Herdecke Heusnerstraße 40 42283 Wuppertal cbiancosino@gmx.de

\section{Abstract \\ $\nabla$}

Background: History, clinical presentation, lung function testing, radiographs including HRCT and nonsurgical biopsy techniques in most cases provide sufficient information for classification of interstitial lung disease (ILD). However, in a small percentage it is not possible to establish the diagnosis so that lung biopsy may be required. We analyzed under which circumstances a reduction of invasive procedures is reasonable.

Methods: Between January 1997 and December 2009 we examined 3399 specimens from 1299 patients with benign inflammatory and granulomatous diseases in whom ILD was clinically hypothesized. We compared the probability of disease according to Bayes before and after surgery which corresponds to the clinical diagnosis (a priori probability) and the final diagnosis (a posteriori probability). Additionally, procedures, operation related complications and the patients' smoking habits were documented.

Results: In 111 patients (8.5\%) surgical evaluation was performed (14 mediastinoscopies, 97 thoracotomies/VATS biopsies). All mediastinoscopies substantiated a epitheloid cell granulomatosis. In $30 \%$ of all VATS procedures a prolonged air leak of more than 4 days was observed. One patient died and one had to get a new chest tube after removal. Changes of a priori/a posteriori probabilities was shown for non-smokers in Wegner's granulomatosis ( 0.6 vs. $2.2 \%$ ) and IPF (16.7 vs. $34.8 \%$ ), for smokers in Langerhans' cell histiocytosis (1.4 vs. $7.8 \%$ ) and IPF (16.7 vs. $33.3 \%$ ). In the majority of cases even a reduction of probability was seen.

Conclusion: Considering complications and limited diagnostic gain, lung biopsies for diagnosis of ILD should be recommended only in selected patients.

\section{Zusammenfassung \\ $\nabla$}

Hintergrund: Anamnese, Klinik, bildgebende, insbesondere HRCT, und klinisch-bioptische Verfahren ermöglichen die Einordnung der Mehrzahl interstitieller Lungenerkrankungen. Am Ende der klinischen Diagnostik bleibt ein kleiner Teil dieser Erkrankungen dennoch ungeklärt und ist Anlass für eine offene Lungenbiopsie. Ziel der vorliegenden Arbeit war es zu prüfen, unter welchen Voraussetzungen eine Reduktion invasiver diagnostischer Eingriffe möglich ist.

Methoden: Zwischen 01/97 und 12/09 wurden 3399 Proben von 1299 Patienten mit benignen entzündlichen und granulomatösen Erkrankungen untersucht, bei denen am Beginn der Untersuchung die klinische Verdachtsdiagnose auf das Vorliegen einer interstitiellen Erkrankung vorlag. Für alle mit diagnostischer Zielsetzung operierten Patienten wurden Art des thoraxchirurgischen Eingriffs, operationsbedingte Komplikationen und Raucheranamnese erfasst. Anschließend berechneten wir die a-priori- und in Abhängigkeit von den ergänzend erfassten Daten die a-posteriori-Wahrscheinlichkeiten für die unterschiedlichen Erkrankungen (Bayes-Theorem).

Ergebnisse: Bei 111 Patienten (8,5\%) erfolgte eine operative Diagnostik (14 Mediastinoskopien, 97 Video-assistierte-Thorakoskopien, -tomien). Alle Mediastinoskopien ergaben eine epitheloidzellige Granulomatose. 30\% aller Thorakoskopien gingen mit einer Fistelproblematik $>4 \mathrm{~d}$ einher. Ein Patient wurde redrainiert, ein Patient verstarb. Änderungen der a-priori-/a-posteriori-Wahrscheinlichkeiten fanden sich bei den Nichtrauchern für Wegenersche Granulomatose (0,6 vs. 2,2\%) und IPF (16,7 vs. $34,8 \%$ ), bei den Rauchern für Histiozytosis X (1,4 vs. 7,8\%) und IPF (16,7 vs. 33,3\%). Bei der Mehrzahl aller anderen interstitieller Erkrankungen reduzierten sich dagegen die a-posteriori- Wahrscheinlichkeiten. 
Schlussfolgerung: Bei klinischem Verdacht auf das Vorliegen einer Lungengerüsterkrankung erfordern Komplikationsrate und limitierter differenzialdiagnostischer Zugewinn eine strenge Indikationsstellung zur invasiven Diagnostik.

\section{Introduction}

$\nabla$

Interstitial lung diseases (ILDs) are a heterogeneous group of pulmonary disorders that are characterized by inflammation and fibrosis primarily of the interstitium, but they can also affect the alveoli, bronchial airways and pulmonary vessels. They are classified together because of similar clinical, roentgenographic, physiologic and pathologic manifestations. In 2002 the American Thoracic Society (ATS) and the European Respiratory Society (ERS) revised the original classification and introduced the diffuse parenchymal lung disease (DPLD) in place of the term ILD. DPLD were classified into 4 categories: (1) DPLDs of known causes like connective tissue diseases, environmental or drug related diseases, (2) granulomatous disorders like sarcoidosis, (3) other and often rare DPLDs like Langerhans' cell histiocytosis and lymphangioleiomyomatosis and (4) the idiopathic interstitial pneumonias (IIPs) which are further subdivided [1].

History, physical examination, serologic studies, pulmonary function tests and chest radiographs are able to narrow the differential diagnosis. High resolution computed tomography (HRCT) can provide essential contributions to the diagnosis of ILDs but concerning sensitivity and specificity in different series it is highly dependent on the population studied and the skill of the interpreting physician [2]. Transbronchial (TBB) or endobronchial biopsies are useful for diagnosing sarcoidosis, infection or malignancy but provide inadequate tissue sampling for fibrosing ILDs because of its patchy appearance.

Although a large number of different ILDs exist, in a specialized centre only a small percentage has to be assessed surgically, because the clinical diagnosis in conjunction with distinct patterns on HRCT in most cases lead to the correct diagnosis.

Surgical lung biopsy has a very high diagnostic yield (>92\%) and a mortality of less than $6 \%[3,4,5]$. Reports about morbidity vary significantly (6-19\%) due to different definitions of morbidity. Additionally, morbidity is also dependent on the final pathologic diagnosis. On this basis in their joint statement the ATS/ERS recommended that "in the absence of contraindications, surgical lung biopsy is advised in patients with suspected IIP who do not show the classic clinical and HRCT picture of IPF/UIP". In general it seems reasonable to push for videothoracoscopic diagnosis in cases of atypical features, progressive course, unexplained extrapulmonary manifestations or suspected malignancies. The advantages of surgical lung biopsies are well worked out in that joint statement.

In our article we focused on their complications and limitations. Reviewing the literature, it remains unclear under which circumstances surgical biopsies which are performed on not representative cohorts of this disease make additional contributions in establishing the etiology and where not.

Additionally, we wanted to determine the incidence of major postoperative complications like death and prolonged air leaks and to analyze the diagnostic gain from these procedures considering the special collective of patients and their smoking habits. We postulate that considering the point of diagnostic chain the patients with DPLD were at, not all diagnoses were equally probable. At the end of clinical work up we have to consider other entities as more probable as at the beginning.
Therefore we compared the probability of disease according to Bayes [5] before and after surgery which corresponds to the clinical diagnosis or the a priori probability and the final diagnosis or the a posteriori probability. If the likelihood of a disease changes as a function of the surgical result, then there is a gain of information. If a prevalence of probability was shown with referral to smoking habits towards a certain entity, then the kind of clinically hypothesized disease would be an important marker whether to push for surgery or not.

These "not entirely benign procedures" like they were assessed by Kreider et al. [6] can only be recommended to patients if the complications are acceptable and the procedures lead to a contribution that has therapeutical consequences.

\section{Materials and methods}

$\nabla$

Between January 1997 and December 2009 at our institution, a total of 3399 specimens from 1299 patients (675 males, $624 \mathrm{fe}$ males; mean \pm SD age, $54.5 \pm 15.5$ yrs) were evaluated. A clinically (group I) and/or histologically (group II) established final diagnosis was available in all patients.

All available diagnostic information was used and all diagnoses were verified by experienced doctors. The samples were catagorised into three groups on the basis of the realization of final diagnosis, clinically confirmed diseases $(n=1188,619$ males, 569 females, $55 \pm 16 \mathrm{yrs}$ ), VATS and or thoracotomy ( $\mathrm{n}=97,48$ males, 49 females, $51 \pm 12$ yrs) and mediastinoscopy ( $\mathrm{n}=14,8$ males, 6 females, $43 \pm 12$ yrs). The second group ( $n=97)$ was divided into smokers $(n=51)$ and nonsmokers $(n=46)$ according to anamnestic data.

\section{Data analysis}

The relative frequencies of final diagnoses, as based on all available information, were taken as estimates of a priori probabilities. The authors then computed $a$ posteriori probabilities according to Bayes rule [5] for each disease within these four groups. A priori and a posteriori probabilities were statistically compared as proportions. No correction for multiple testing was made, as no rational choice for multiplicity seemed possible; instead, comparisons showing $\mathrm{p}<0.005$ were marked separately in the tables. These data were compared between final diagnoses by Chi-Quadrat Test using Yates-correction. In all analyses, statistical significance was assumed for $\mathrm{p}<0.0025$.

\section{Results}

$\nabla$

Our series included 1299 patients with a median age of 56.3 years (range 8-89 years) whereof $52 \%$ were male and $48 \%$ were female patients.

In 1188 cases a diagnosis was established on the basis of the clinical diagnosis in conjunction with radiographic findings (group I). During the study period, 111 patients (9\%) underwent surgical evaluation, 14 via mediastinoscopy, 97 patients via thoracotomy/VATS procedure. All surgical procedures yielded a definitive diagnosis for the patients. All mediastinoscopies substantiated an epitheloid cell granulomatosis (13 sarcoidosis, 1 tuberculosis). Among the 97 patients, 16 conditions were identified. In the majority of all surgical cases an IPF was detected (29.7\%), followed by sarcoidosis (18.9\%), EAA (9.0\%), NSIP (9.0\%), tuberculosis $(7.2 \%)$. 


\begin{tabular}{|c|c|c|c|c|c|}
\hline & $\begin{array}{l}\text { All Subjects } \\
\mathrm{n}\end{array}$ & Group I & $\begin{array}{l}\text { VATS } \\
\text { Nonsmoker }\end{array}$ & $\begin{array}{l}\text { Group II } \\
\text { VATS } \\
\text { Smoker }\end{array}$ & Mediastinoscopy \\
\hline Asthma bronchiale & 17 & 17 & 0 & 0 & 0 \\
\hline COPD & 63 & 63 & 0 & 0 & 0 \\
\hline Pneumonia & 65 & 59 & 1 & 4 & 0 \\
\hline Sarcoidosis & 478 & 457 & 3 & 5 & 13 \\
\hline Berylliosis & 1 & 0 & 1 & 0 & 0 \\
\hline NSG & 2 & 0 & 1 & 1 & 0 \\
\hline Tuberculosis & 12 & 4 & 4 & 3 & 1 \\
\hline Suspicious tuberculosis & 5 & 5 & 0 & 0 & 0 \\
\hline Siderosis & 2 & 2 & 0 & 0 & 0 \\
\hline Asbestosis & 4 & 4 & 0 & 0 & 0 \\
\hline Silicosis & 3 & 3 & 0 & 0 & 0 \\
\hline Mycotic lung infections & 1 & 0 & 1 & 0 & 0 \\
\hline Vascular disease & 5 & 5 & 0 & 0 & 0 \\
\hline Wegener's granulomatosis & 8 & 7 & 1 & 0 & 0 \\
\hline Eosinophilic pneumonia & 7 & 5 & 2 & 0 & 0 \\
\hline Non characteristic findings & 23 & 23 & 0 & 0 & 0 \\
\hline Drug-induced pulm. disease & 15 & 15 & 0 & 0 & 0 \\
\hline COP & 53 & 50 & 2 & 1 & 0 \\
\hline Histiozytosis X & 18 & 14 & 0 & 4 & 0 \\
\hline Idiopathic pulmonary fibrosis & 217 & 184 & 16 & 17 & 0 \\
\hline NSIP & 92 & 82 & 4 & 6 & 0 \\
\hline EAA & 131 & 121 & 6 & 4 & 0 \\
\hline Diff. alv. hemorrhage syndrome & 10 & 10 & 0 & 0 & 0 \\
\hline Connective tissue disease & 44 & 39 & 3 & 3 & 0 \\
\hline LIP & 10 & 9 & 1 & 0 & 0 \\
\hline Alveolarproteinosis & 5 & 5 & 0 & 0 & 0 \\
\hline RBILD & 8 & 5 & 0 & 3 & 0 \\
\hline Summary & 1299 & 1188 & 46 & 51 & 14 \\
\hline
\end{tabular}

Table 1 Number of interstitial lung disease (ILD) as a function of the special kind of the validation of final diagnosis (group I patients with clinically verified, group II surgical verified final diagnosis)

COPD: chronic obstructive pulmonary disease; COP: cryptogenic organising pneumonia; EAA: extrinsic allergic alveolitis; NSIP: nonspecific interstitial pneumonia; LIP: lymphocytic interstitial pneumonia; RBILD: respiratory bronchiolitis interstitial lung disease, NSG: necrotizing sarcoid granulomatosis.

In the nonsurgical group I sarcoidosis most frequently noted (38.5\%), followed by IPF (15.5\%), EAA (10.2\%) and NSIP (6.9\%), whereas in the VATS group IPF was ahead (34.0\%), followed by EAA (10.3\%) and sarcoidosis (8.2\%). About half of the thoracoscopically evaluated patients were smokers (50.8\%). Details of distribution are summarized in $\bullet$ Table 1 .

Changes of $a$ priori and $a$ posteriori probabilities according to smoking status are shown in Table2. Whereas the likelihood for Wegener's granulomatosis increased in nonsmokers from 0.6 to $2.2 \%$ non significantly, there were highly significant differences regarding a priori and a posteriori probabilities for IPF (16.7 to $34.8 \% ; \mathrm{p}=.0017)$. Interestingly, the likelihood for Langerhans' cell histiocytosis rose in smokers from 1.4 to $7.8 \%$ and for IPF from 16.7 to $33.3 \%(p=.0006)$. In the majority of cases even a reduction of probability was seen.

The overall mortality rate was low in our population, with only one death (1.4\%).

In $30 \%$ of all VATS procedures a prolonged air leak of more than 4 days was observed ( $\bullet$ Table 3 ) and one patient had to get a new chest tube after removal because of consecutive pneumothorax. One patient developed a temporary chylothorax which, however, could be managed dietarily.

\section{Discussion}

In this retrospective analysis we wanted to demonstrate that considering the point of diagnostic chain the patients with ILD are at, not all diagnoses are equally probable.

By help of our data the clinician is able to narrow his diagnostic focus and therefore re-evaluate the necessity of surgical lung biopsy.

When pursuing diagnostical lung biopsy the potential benefits have to be weighed against the risks of the procedure. Noninvasive approaches like TBB mostly contribute only limited data so that surgical biopsy is taken into consideration when no clear diagnosis can be established. The advantage is that surgical biopsy almost uniformly results in a precise diagnosis, even in cases of rare diseases, the clinician can better design more accurate treatment regimens with higher therapeutical yield and lower undesirable side effects and give detailed advice to the patients regarding outcome and prognosis.

Special consideration should be given to patients with cardiovascular and pulmonary impairment, like preoperative ventilator dependence, immunocompromised status, a diffusing capacity of less than $35 \%$ and pulmonary hypertension, as they appear to be at greater risk for complications of surgical biopsy [4,6-8]. In our separate analysis of the surgical group we examined to what extent the deterioration of lung function parameters might be associated to the prevalence of complications. Actually, we could not identify a significant correlation which may be due to the small case numbers or to the limited value of lung function 


\begin{tabular}{|c|c|c|c|c|c|}
\hline & \multirow{2}{*}{$\begin{array}{l}\text { probability } \\
\text { a priori } \\
\mathrm{n}\end{array}$} & \multicolumn{4}{|c|}{ a posteriori probability } \\
\hline & & Group I & $\begin{array}{l}\text { VATS } \\
\text { Nonsmoker }\end{array}$ & $\begin{array}{l}\text { Group II } \\
\text { VATS } \\
\text { Smoker }\end{array}$ & Mediastinoscopy \\
\hline Asthma bronchiale & 1.3 & 1.4 & 0.0 & 0.0 & 0.0 \\
\hline COPD & 4.8 & 5.3 & 0.0 & 0.0 & 0.0 \\
\hline Pneumonia & 5.0 & 5.0 & 2.2 & 7.8 & 0.0 \\
\hline Sarcoidosis & 36.8 & 38.5 & $6.5^{*}$ & $9.8^{*}$ & $92.9^{*}$ \\
\hline Berylliosis & 0.1 & 0.0 & 2.2 & 0.0 & 0.0 \\
\hline NSG & 0.2 & 0.0 & $2.2^{*}$ & $2.0^{*}$ & 0.0 \\
\hline Tuberculosis & 0.9 & 0.3 & $8.7^{*}$ & $5.9^{*}$ & 7.1 \\
\hline Suspicious tuberculosis & 0.4 & 0.4 & 0.0 & 0.0 & 0.0 \\
\hline Siderosis & 0.2 & 0.2 & 0.0 & 0.0 & 0.0 \\
\hline Asbestosis & 0.3 & 0.3 & 0.0 & 0.0 & 0.0 \\
\hline Silicosis & 0.2 & 0.3 & 0.0 & 0.0 & 0.0 \\
\hline Mycotic lung infections & 0.1 & 0.0 & 2.2 & 0.0 & 0.0 \\
\hline Vascular disease & 0.4 & 0.4 & 0.0 & 0.0 & 0.0 \\
\hline Wegener's granulomatosis & 0.6 & 0.6 & 2.2 & 0.0 & 0.0 \\
\hline Eosinophilic pneumonia & 0.5 & 0.4 & 4.3 & 0.0 & 0.0 \\
\hline Non characteristic BAL & 1.8 & 1.9 & 0.0 & 0.0 & 0.0 \\
\hline Drug-induced pulm. disease & 1.2 & 1.3 & 0.0 & 0.0 & 0.0 \\
\hline COP & 4.1 & 4.2 & 4.3 & 2.0 & 0.0 \\
\hline Histiozytosis X & 1.4 & 1.2 & 0.0 & $7.8^{*}$ & 0.0 \\
\hline Idiopathic pulmonary fibrosis & 16.7 & 15.5 & $34.8^{*}$ & $33.3^{*}$ & 0.0 \\
\hline NSIP & 7.1 & 6.9 & 8.7 & 11.8 & 0.0 \\
\hline EAA & 10.1 & 10.2 & 13.0 & 7.8 & 0.0 \\
\hline Diff. alv. hemorrhage syndrome & 0.8 & 0.8 & 0.0 & 0.0 & 0.0 \\
\hline Connective tissue disease & 3.4 & 3.3 & 6.5 & 5.9 & 0.0 \\
\hline LIP & 0.8 & 0.8 & 2.2 & 0.0 & 0.0 \\
\hline Alveolarproteinosis & 0.4 & 0.4 & 0.0 & 0.0 & 0.0 \\
\hline RBILD & 0.6 & 0.4 & 0.0 & $5.9^{*}$ & 0.0 \\
\hline Summary & 100.0 & 100.0 & 100.0 & 100.0 & 100.0 \\
\hline
\end{tabular}

Table 2 Probability (in \%) of interstitial lung disease (ILD) as a function of the special kind of the validation of final diagnosis (group I patients with clinical verified, group II surgical verified final diagnosis).

Data are presented as \%, unless otherwise stated. Abbreviations: COPD: chronic obstructive pulmonary disease; COP: cryptogenic organising pneumonia; EAA: extrinsic allergic alveolitis; NSIP: nonspecific interstitial pneumonia; LIP: lymphocytic interstitial pneumonia; RBILD: respiratory bronchiolitis interstitial lung disease, NSG: necrotizing sarcoid granulomatosis.

${ }^{*} \mathrm{p}<0.0025$ versus the respective a priori value.

Table 3 Complication of thoracic surgery - duration of drainage (d).

\begin{tabular}{lccllc}
\hline & $\mathbf{1 - 4 d}$ & $\mathbf{> 4 d}$ & $\mathbf{> 6 d}$ & $\mathbf{> 8 d}$ & \\
& $\mathbf{n}_{\mathbf{1}}$ & $\mathbf{n}_{\mathbf{2}}$ & $\mathbf{n}_{\mathbf{3}}$ & $\mathbf{n}_{\mathbf{4}}$ & $\mathbf{n}$ \\
\hline Pneumonia & 3 & 1 & 0 & 1 & 5 \\
\hline Sarcoidosis & 5 & 1 & 0 & 2 & 8 \\
\hline Tuberculosis & 4 & 2 & 0 & 1 & 7 \\
\hline NSG & 2 & 0 & 0 & 0 & 2 \\
\hline Berylliosis & 1 & 0 & 0 & 0 & 1 \\
\hline Mycotic lung infections & 1 & 0 & 0 & 0 & 1 \\
\hline Wegener's granulomatosis & 1 & 0 & 0 & 0 & 1 \\
\hline Eosinophilic pneumonia & 2 & 0 & 0 & 0 & 2 \\
\hline COP & 0 & 1 & 1 & 1 & 3 \\
\hline Histiozytosis X & 4 & 0 & 0 & 0 & 4 \\
\hline Idiopathic pulmonary fibrosis & 24 & 3 & 3 & 3 & 33 \\
\hline NSIP & 8 & 0 & 2 & 0 & 10 \\
\hline EAA & 6 & 1 & 2 & 1 & 10 \\
\hline Connective tissue disease & 4 & 1 & 1 & 0 & 6 \\
\hline LIP & 1 & 0 & 0 & 0 & 1 \\
\hline RBILD & 2 & 1 & 0 & 0 & 3 \\
\hline Summary & 68 & 11 & 9 & 9 & 97
\end{tabular}

COPD: chronic obstructive pulmonary disease; COP: cryptogenic organising pneumonia; EAA: extrinsic allergic alveolitis; NSIP: nonspecific interstitial pneumonia; LIP: Iymphocytic interstitial pneumonia; RBILD: respiratory bronchiolitis interstitial lung disease; NSG: necrotizing sarcoid granulomatosis. parameters regarding this topic. Possibly, an analysis of the lung's compliance, which is an informative parameter for the lung's stiffness, could show a significant correlation to postoperative complications with regard to healing of the suture line.

Generally, many studies conclude in accordance with the recommendation of the ATS/ERS that lung biopsy is safe in most cases and should be used to assess patients where the diagnosis remains unclear after thorough clinical investigation. However, Kreider et al. [6] calculated a composite postoperative mortality rate of $4.5 \%$ for 2223 patients in their meta-analysis of 23 studies and therefore concluded that "lung biopsy for diagnosis of ILD $[\ldots]$ is not an entirely benign procedure".

Although reports about morbidity vary significantly (6-19\%) due to different definitions of morbidity ranging from mechanical ventilation postoperatively, pneumonia, nosocomial infections, prolonged air leak from the chest tube, and other commonly accepted postoperative complications like myocardial infarction and hospital readmission for pneumothorax, respiratory failure, they must not be underestimated $[3,4,6]$.

In our population the overall mortality was rather low $(1.4 \%)$, with only one death. This is surely due to the fact that none of our patients required mechanical ventilation or severe immunosuppression before surgery which are the most important predictors of perioperative mortalitiy. Kreider et al. found similar values in their meta-analysis for patients who were free from ventilation $(2,2 \%)$. 


\begin{tabular}{|lccccc|}
\hline Diagnosis & Symptom. & Antituberc. & Prednisolon* & Chemotherapy & $\mathbf{n}^{*}$ \\
\hline Pneumonia & 3 & 0 & 2 & 0 & 5 \\
\hline Sarcoidosis & 14 & 0 & 7 & 0 & 21 \\
\hline NSG & 1 & 0 & 1 & 0 & 2 \\
\hline Berylliosis & 1 & 0 & 0 & 0 & 1 \\
\hline Tuberculosis & 2 & 4 & 2 & 0 & 8 \\
\hline Mycotic lung infections & 0 & 0 & 1 & 0 & 1 \\
\hline Wegener's Granulomatosis & 0 & 0 & 0 & 1 & 1 \\
\hline Eosinophilic Pneumonia & 0 & 0 & 2 & 0 & 2 \\
\hline BOOP & 0 & 0 & 3 & 0 & 3 \\
\hline Histiozytosis X & 4 & 0 & 0 & 0 & 4 \\
\hline Usual Interstitial Pneumonia & 6 & 0 & 19 & 8 & 33 \\
\hline NSIP & 4 & 1 & 5 & 0 & 10 \\
\hline EAA & 2 & 0 & 8 & 1 & 11 \\
\hline Connective tissue disease & 2 & 0 & 2 & 1 & 5 \\
\hline LIP & 0 & 0 & 1 & 0 & 1 \\
\hline RBILD & 2 & 0 & 1 & 0 & 3 \\
\hline Summary & 41 & 5 & 54 & 11 & 111 \\
\hline
\end{tabular}

Table 4 Disease related kind of therapy (group II).

COP: cryptogenic organising pneumonia; EAA: extrinsic allergic alveolitis; NSIP: nonspecific interstitial pneumonia; LIP: lymphocytic interstitial pneumonia; RBILD: respiratory bronchiolitis interstitial lung disease; NSG: necrotizing sarcoid granulomatosis.

* Prednisolon $(7.5-50 \mathrm{mg} / \mathrm{d})$

\# Chemotherapy (Azathioprin, Pentoxifyllin, Colchicin, Imurek, Cyclophosphamid)

Moreover, refinements of HRCT lead to an increasing reservation towards surgical lung biopsy and even to the suggestion that an accurate diagnosis of ILD could be made without surgery [9].

Raghu et al. found out that specificity of diagnosis with IPF based on clinical assessment and HRCT in a specialized centre is above $90 \%$, but sensitivity is rather low [10]. They conclude that "not all patients with new-onset IPF require lung biopsy for diagnosis, but a diagnosis of IPF will be missed in nearly one third of cases" so that biopsy "is indicated in patients with ILD in whom the diagnosis is unclear".

In this context it would be interesting to know under which circumstances it is reasonable to refrain from surgery because no additional contributions are expected.

We analyzed the diagnostic gain from these procedures considering the special collective of patients and their smoking habits. We compared the probability of disease according to Bayes [5] before and after surgery which corresponds to the clinical diagnosis (a priori probability) and the final diagnosis (a posteriori probability). If the likelihood of a disease changes as a function of the surgical result, then there is a gain of information. If a prevalence of probability was shown with referral to smoking habits towards a certain entity, then the kind of clinically hypothesized disease would be an important marker whether to push for surgery or not.

An important observation was the fact that considering the point of diagnostic chain the patients with ILD were at, not all diagnoses were equally probable. That means that after painstaking clinical evaluation by help of history, physical examination, serologic studies, pulmonary function tests, chest radiographs including HRCT and TBB for exclusion of sarcoidosis and malignant disease it is possible to reach a diagnosis in most cases or at least to narrow the differential diagnoses. Thus, at the end of clinical work up we have to consider other entities as more probable as at the beginning. When establishing the clinical hypothesis the clinician has to bear in mind that he has to put special attention to a selected quantity of diseases and that for even less the probability of disease changes significantly after surgical confirmation when including the patients' smoking habits.
By help of our data the clinician is able to narrow his diagnostic focus and therefore re-evaluate the necessity of surgical lung biopsy. That is gaining even more importance when considering which limited therapeutic alternatives one can offer with regard to the highly selective groups at the time before evaluating surgery $(\bullet$ Table 4$)$.

Our results demonstrate a significantly altered likelihood of only a few diseases with regard to the patients' smoking status. The likelihood for Wegner's granulomatosis increased in nonsmokers from 0.6 to $2.2 \%$ and for IPF from 16.7 to $34.8 \%$. Interestingly, the likelihood for Langerhans'cell histiocytosis rose in smokers from 1.4 to $7.8 \%$ and for IPF from 16.7 to $33.3 \%$. In the majority of cases even a reduction of probability was seen.

The four most frequent diseases, sarcoidosis, IPF, EAA and NSIP in the nonsurgical group and IPF, sarcoidosis and EAA in the surgical group covered approximately $72 \%$ of all ILDs. The remaining cases were represented by a wide variety of less frequent or rare ILDs.

Remarkably, in our group II we found a relatively high number of patients diagnosed with sarcoidosis. This can be explained by the long observational period and the advent of new diagnostic tools, especially with regard to mediastinal lymphadenopathy. Today EBUS-FNA as a less invasive procedure has gained rising importance and its utility in the diagnosis not only of mediastinal but also of endobronchial and peripheral lesions has been reported in research publications and confirmed with widespread clinical experience [ $11-13]$. Nevertheless, especially in cases where sarcoidosis patients present at stage 3 or 4 of the radiological classification a surgical confirmation by videothoracoscopic biopsy might be indispensable.

The current study does not deny the value of open lung biopsy in the diagnosis of rare diseases, either by inclusion or exclusion of diagnoses. But, although the enhancement of probability of rare diseases could be important, nearly all of them remained unlikely after our analysis.

In summary, the data of our study suggest that surgical lung biopsies in ILDs make diagnostic contributions with relevant changes in a posteriori probabilities only in special circumstances. 
This study was supported by Landesversicherungsanstalt (LVA), Hamburg, Germany.

\section{Conflict of interest}

$\nabla$

No conflict of interest to be disclosed.

\section{References}

1 Travis WD, King TEJr, Batenan $F$ et al. Consensus classification of the idiopathic interstitial pneumonias. Am J Respir Crit Care Med 2002; 165: $227-304$

2 Hunninghake GW, Lynch DA, Galvin JR et al. Radiologic findings are strongly associated with a pathologic diagnosis of interstitial pneumonias. Chest 2003; 124: 1215-1223

3 Lee YC, Wu CT, Hsu HH et al. Surgical lung biopsy for diffuse pulmonary disease: Experience of 196 patients. J Thorac Cardiovasc Surg 2005; 129: $984-990$

4 Lettieri CJ, Veerapan GR, Helman DL et al. Outcomes and safety of surgical lung biopsy for interstitial lung disease. Chest 2005; 127: 1600

5 Welker L, Jörres RA, Costabel $U$ et al. Predictive value of BAL cell differentials in the diagnosis of interstitial lung diseases. Eur Respir J 2004; 24: $1000-1006$
6 Kreider ME, Hansen-Flaschen J, Ahmad NN et al. Complications of video-assisted thoracoscopic lung biopsy in patients with interstitial lung disease. Ann Thorac Surg 2007; 83: 1140-1144

7 Carillo G, Estrada A, Pedroza J et al. Preoperative risk factors associated with mortality in lung biopsy patients with interstitial lung disease. J Invest Surg 2005; 18: 39-45

8 Utz JP, Ryu JH, Douglas WW et al. High short-term mortality following lung biopsy for interstitial pneumonia. Eur Respir J 2001; 17: 175 - 179

9 Raghu G. Interstitial lung disease: a diagnostic approach - are CT scan and lung biopsy indicated in every patient? Am J Respir Crit Care Med 1995; 151: 909-914

10 Raghu G, Mageto YN, Lockhart $D$ et al. The accuracy of the clinical diagnosis of new-onset idiopathic pulmonary fibrosis and other interstitial lung disease. Chest 1999; 116: $1168-1174$

11 Wang KP, Terry PB. Transbronchial needle aspiration in the diagnosis and staging of bronchogenic carcinoma. Am Rev Respir Dis 1983; 127: $344-347$

12 Sharafkhaneh $A$, Baaklini $W$, Gorin $A B$ et al. Yield of transbronchial needle aspiration in diagnosis of mediastinal lesions. Chest 2003; 124: $2131-2135$

13 Hsu LH, Liu CC, Ko JS. Education and experience improve the performance of transbronchial needle aspiration: a learning curve at a cancer center. Chest 2004; 125: 532 - 540 